\title{
Acceptance of Health Information System for Public Health Centre in North Borneo, Indonesia
}

\author{
Nurul Irma Kusumawati and Sulistyawati \\ Department of Public Health, Universitas Ahmad Dahlan, Yogyakarta, Indonesia
}

\begin{tabular}{l} 
Article Info \\
\hline Article history: \\
Received Jul 14, 2018 \\
Revised Sep 3, 2018 \\
Accepted Sep 27, 2018 \\
\hline
\end{tabular}

\section{Keyword:}

Health information system Health information technology Public health center

\begin{abstract}
This study sought the factor associated with own acceptance of HIS for PHC by using the modification of Technology Acceptance Model (TAM) in the Sebengkok PHC, Central Tarakan Subdistrict, Tarakan City, North Borneo, Indonesia. A cross-sectional approach was conducted through a survey on the 37 of PHC's user. A set of questionnaires which was adopted from the previous research was used to collect the information from the participant. The model was developed by involving job relevance, output quality, result demonstrability, screen design, terminology, facilitating condition, perceived of usefulness, perceived ease of use, intention to use and system use (actual usage) as the construct. According to the hypothesis testing, perceived usefulness predicted by terminology, perceived ease of use is significantly predicted by screen design and terminology, perceived usefulness significantly predicts the intention of use and perceived ease of use, while system use which predicted considerably by the intention of use and facilitating condition. This study may have a contribution to the future improvement of HIS for PHC and guide the next coming research to dig the difference acceptance among the user.
\end{abstract}

Copyright $(2018$ Institute of Advanced Engineering and Science. All rights reserved.

\section{Corresponding Author:}

Sulistyawati,

Department of Public Health, Universitas Ahmad Dahlan,

UAD 3rd Campus, Janturan, Umbulharjo, Yogyakarta 55166, Indonesia.

Email: sulistyawatisuyanto@gmail.com

\section{INTRODUCTION}

The growth of population in developing country must be balanced with the excellent data collection to support the policymaker to provide a health service. Health Information System or Healthcare Information system (HIS) is a function to collect, compile, quality assurance, analyse and disseminate and sharing use of data [1] from the healthcare facilities for policy purposes. HIS has grown dramatically since 1960 worldwide [2] as an effort to provide a reliable data for the policymaker purposes. However, in some developing countries like Indonesia, rising a challenge on HIS implementation, such as the poor data quality. Thus regarding the lack of quality personnel and in proper infrastructure [3], [4].

As the fourth most populous country in the world with more than 260 millions population [5], Indonesia may contribute the significant health metric globally. For that reason, collecting reliable data is a must. In order bridge that purpose, Indonesia government launched Health Information System in Primary Health Centre (HISPHC) or "SIMPUS" which is connected to the District Health Office Information System also the upper level [6]. HISPHC was initiated in 2010 by the Indonesia Ministry of Health [7] which is implemented in 9.655 PHC in Indonesia [8]. In 2014, Indonesia released Indonesia Health Insurance or called as BPJS in which need adequate data from the HISPHC. Accordingly, the role of HISPHC become essential to provide adequate and validate data related to the health aspect. However, amount research in some areas in Indonesia reported there was some challenge of HISPHC implementation. For example, a study in Mulyorejo PHC, Surabaya found that HISPHC has not been used routinely due to some trouble, human experience and 
acceptance were other challenges of the implementation [9]. As a result, there is a necessity to update information regarding the current situation of the HISPHC acceptance to establish evidence as an input for the health authorities.

Sebengkok Public Health Centre located in Central Tarakan Subdistrict, Tarakan City, North Borneo, Indonesia. This PHC may represent the urban PHC in Indonesia, has been implementing HISPHC since 2011. The HIS that they used has being integrated among the division in the PHC such as in registration patient, general polyclinic, hospitalisation services, laboratory and pharmacy. Despite the HIS implementation is remain running, but they still face some challenges such as 1) the unstable of electricity, so occasionally manual record had to perform to make the patient service remain running; 2) no specific staff operates the HIS. To the best of our knowledge, the same problem was found in the another PHC in Indonesia, but little research was performed. Accordingly, this study could stand for the other areas with the similar characteristic and the corresponding problem.

By using modification of Technology Acceptance Model (TAM) which is developed by [10], this study aims to observe the factor associated with individual acceptance of HISPHC through some construct such as job relevance, output quality, result demonstrability, screen design, terminology, facilitating condition, perceived of usefulness, perceived ease of use, intention to use and system use (actual use). The urgency of this research due to the importance of system use (practical use) to carried out the system implementation successful.

\section{RESEARCH METHOD}

Cross-sectional approach by performing a survey was applied in December 2017 in Sebengkok Public Health Centre (PHC), Tarakan Subdistrict, Tarakan City, North Borneo, Indonesia. Modification of original Technology Acceptance Model (TAM) was used to measure the technology acceptance among PHC's user, i.e. physician, nurse, midwife, pharmacies, nutrition officer, public health officer and register patient staff.

Slovin calculator (http://www.en.globalstatistik.com/sampling-size-calculator/) was used to count the sample size based on $10 \%$ of margin error. Accordingly, the sample was 37 participants out of 59 people who is everyone ever been exposed by PHC's information system. The sample was chosen through accidental sampling. We added $10 \%$ of the sample size to anticipate drop out due to the incompleteness of data.

A set of questionnaires which was adopted from previous research was used to obtain the data from the participant. The questionnaire validity value is more than 0.5 for each construct question and Cronbach`s Alpha- Composite Reliability was more than 0.7 [11]. The questionnaire consisted of two sections, i.e. sociodemographic participant and research variable. Twenty-six statements in which served on Likert Scale was asked to the participant. Likert scale was score 1 for very disagree, 2 for disagree, 3 for neutral, 4 for agree and 5 for very agree. Dependent, independent variable, construct and question for each construct are presented in Table 1.

The analysis was performed in Smart PLS 3.2.3 trial version by following these steps: 1) univariate analysis, 2) evaluation model (outer model): convergent and discriminant validity, reliability construct, 3) evaluation structure model (inner model): using R square, 4) hypothesis testing. The hypothesis was accepted through Bootstrapping test with $\mathrm{t}$-value $>1.96$ which is equivalent to $\mathrm{p}<0.05$. This research was approved by the public health faculty committee. Informed consent was asked from each participant prior to the interview.

\section{RESULTS AND ANALYSIS}

A 37-participant has participated in this research. Most of them were female, and more than $90 \%$ of the participant was aged between 30-49. Only 5 participants hold on senior high school education while the rest was at diploma or bachelor. Majority of the participant was a nurse and followed by the midwife as shown in Table 2.

Univariate analysis tells that the majority of participant accepted the PHC's information system that they have been used. Thus, be reflected by the mean score which is more than 3 for each indicator. Afterwards, entirely studied constructs were valid. It is shown from Cronbach Alpha, AVE and Composite Reliability are $>0.6,>0.5$ and $>0.7$ respectively such as explained in (12) as shown in Table 3 .

Refer to the previous study, convergent validity was assessed through loading factor value by considering loading factor more than $>0.7$ was accepted [13]. On this research, entirely sub construct embrace $>0.7$ of loading factor. Accordingly, they were accepted as sub construct to develop the model. To assess the power of the model, we took into consideration the $\mathrm{R}$ square value. Among the dependent variable, Perceived usefulness, Perceived ease of use, Intention to use and System use had R square more than 0.8, this 
number shows that the independent variable (sub-construct) could explain the dependent variable (construct) amount more than $64 \%$. While the $36 \%$ is explained by other factors as shown in Figure 1.

Table 1. Structure Item for Each Construct

\begin{tabular}{|c|c|c|c|c|}
\hline No & Variable & Construct & Code & Statements \\
\hline 1 & IV & Job Relevance & JR1 & In my job, using PHC's information system is very important \\
\hline 2 & IV & & JR2 & In my job, using PHC's information system is very relevant \\
\hline 3 & IV & Output Quality & OQ1 & I don't have any problem with PHC's information system output \\
\hline 4 & IV & & OQ2 & I don't have any problem with output quality of PHC's information system \\
\hline 5 & IV & Result Demonstrability & RD1 & The result of using PHC's information system is applicable for me \\
\hline 6 & IV & & $\mathrm{RD} 2$ & $\begin{array}{l}\text { I believe can communicate with other regarding consequences of using } \\
\text { PHC's information system }\end{array}$ \\
\hline 7 & IV & Screen Design & SD1 & PHC's information system display is consistent \\
\hline 8 & IV & & $\mathrm{SD} 2$ & Instruction on PHC's information system is placed in the right button \\
\hline 9 & IV & Terminology & TM1 & I understand the terminology used in PHC's information system \\
\hline 10 & IV & & TM2 & $\begin{array}{l}\text { In my opinion, the terminology used in PHC's information system is } \\
\text { consistent }\end{array}$ \\
\hline 11 & IV & Facilitating Condition & $\mathrm{FC} 1$ & The existing resources support the usage of PHC's information system \\
\hline 12 & IV & & FC2 & I have appropriate knowledge for using PHC's information system \\
\hline 13 & IV & & FC3 & $\begin{array}{l}\text { IT staff in district health office be able to help if I found difficulties in using } \\
\text { PHC's information system }\end{array}$ \\
\hline 14 & DV & Perceived Usefulness & PU1 & Using PHC's information system increases my work productivity \\
\hline 15 & DV & & PU2 & Using PHC's information system increases my work effectivity \\
\hline 16 & DV & Perceived Ease of Use & PEU1 & PHC's information system is easy to use \\
\hline 17 & DV & & PEU2 & Usage of PHC's information system is don't need high effort \\
\hline 18 & DV & Intention to Use & IU1 & I am interested in using PHC's information system in the next three months \\
\hline 19 & DV & & IU2 & I predict that I will use PHC's information system in the next three months \\
\hline 20 & DV & & IU3 & I plan to use PHC's information system in the next three months \\
\hline 21 & DV & & SU1 & I use PHC's information system neither in my daily work nor holiday \\
\hline 22 & DV & System Use (Actual & SU2 & I always use PHC's information system for data entry purposes \\
\hline 23 & DV & Use) & SU3 & I use PHC's information system in my every work \\
\hline 24 & DV & & SU4 & I use PHC's information system average 10 minutes for a section \\
\hline 25 & DV & & SU5 & Overall, I satisfy with the PHC's information system performance \\
\hline 26 & DV & & SU6 & $\begin{array}{l}\text { I will communicate my satisfaction on using PHC's information system to } \\
\text { my colleagues }\end{array}$ \\
\hline
\end{tabular}

Table 2. Socio-Demographic of Participant

\begin{tabular}{llcc}
\hline \multirow{3}{*}{ Gender } & Demographic & Frequency & Percentage (\%) \\
& Female & 31 & 83.8 \\
Mge & Total & 6 & 16.2 \\
& $<30$ & 37 & 100 \\
Education & $30-49$ & 2 & 5.4 \\
& $>50$ & 34 & 91.9 \\
& Total & 1 & 2.7 \\
& Senior high school & 37 & 100 \\
Occupation & Diploma & 5 & 13.5 \\
& Bachelor & 14 & 37.8 \\
& Total & 18 & 48.6 \\
& General practitioner & 37 & 100 \\
& Nurse & 3 & 8.1 \\
& Dentist & 14 & 37.8 \\
& Midwife & 1 & 2.7 \\
& Pharmacist assistance & 9 & 24.3 \\
& Administration staff & 1 & 2.7 \\
& Manager assistance & 2 & 5.4 \\
& Nutritionist & 1 & 2.7 \\
& Environmental health staff & 2 & 5.4 \\
& Pharmacist & 1 & 2.7 \\
& Health analyst & 1 & 2.7 \\
& Total & 2 & 5.4 \\
& & 37 & 100 \\
\hline
\end{tabular}


Table 3. The Relationship among Studied Construct

\begin{tabular}{cccc}
\hline & CA & CR & AVE \\
\hline FC & 0.875 & 0.923 & 0.800 \\
IU & 0.920 & 0.949 & 0.862 \\
JR & 0.826 & -0.920 & 0.852 \\
OQ & 0.854 & 0.932 & 0.872 \\
PEU & 0.899 & 0.952 & 0.908 \\
PU & 0.769 & 0.896 & 0.812 \\
RD & 0.890 & 0.948 & 0.901 \\
SD & 0.609 & 0.836 & 0.719 \\
SU & 0.966 & 0.973 & 0.855 \\
TM & 0.715 & 0.875 & 0.778
\end{tabular}

CA: Cronbach's alpha; CR: Composite reliability; AVE: average variance extracted

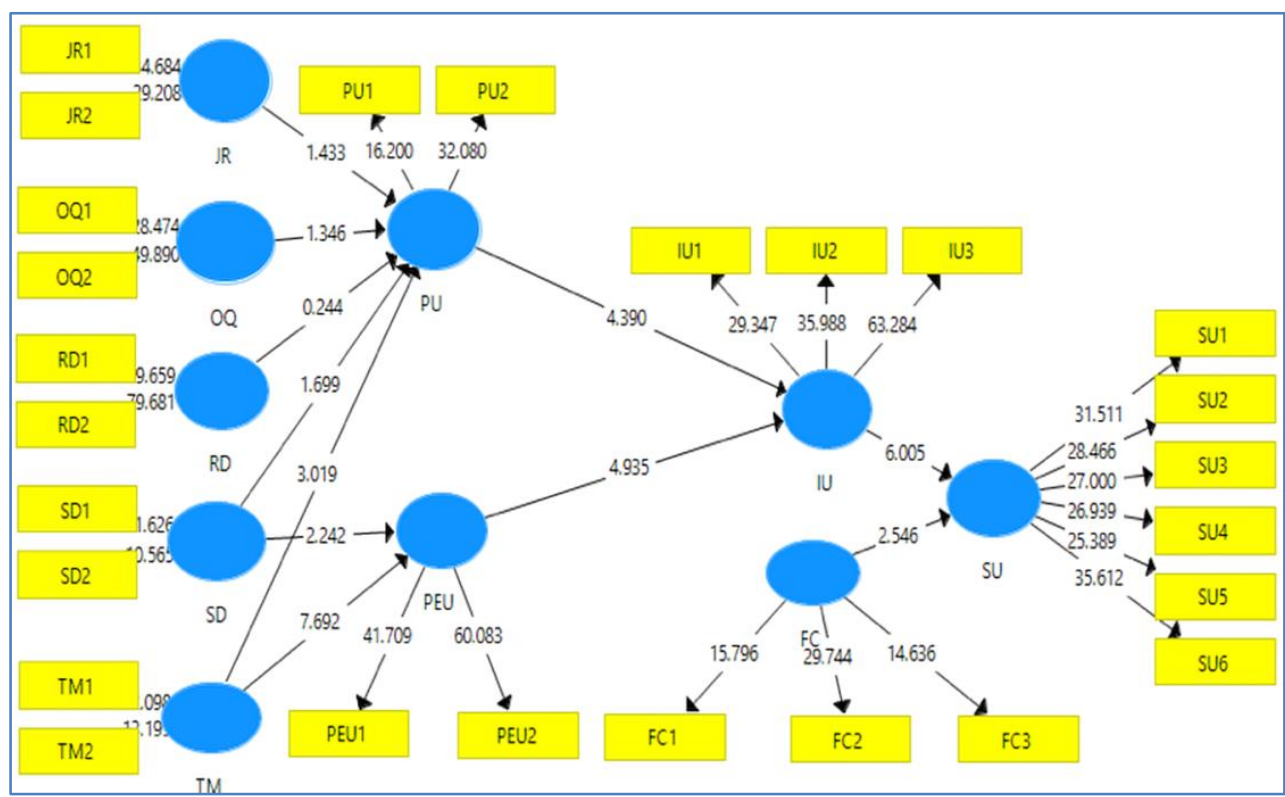

Figure 1. Bootstrapping model result

According to the hypothesis testing of the structural model (Bootstrapping model), the entire sub construct has a positive effect to construct. Additionally, perceived usefulness only predicted by terminology, perceived ease of use is significantly predicted by screen design and terminology, the intention of use is significantly predicted by perceived usefulness and perceived ease of use, last is the system use which significantly predicted by the intention of use and facilitating condition as shown in Table 4.

Table 4. Hypothesis Testing Result

\begin{tabular}{cc}
\hline Construct & t-statistic \\
\hline JR $\rightarrow$ PU & 1.433 \\
OQ $\rightarrow$ PU & 1.346 \\
$\mathrm{RD} \rightarrow$ PU & 0.244 \\
$\mathrm{SD} \rightarrow \mathrm{PU}$ & 1.699 \\
$\mathrm{TM} \rightarrow \mathrm{PU}$ & $3.019^{*}$ \\
$\mathrm{TM} \rightarrow \mathrm{PEU}$ & $7.692^{*}$ \\
$\mathrm{SD} \rightarrow \mathrm{PEU}$ & $2.242^{*}$ \\
$\mathrm{PU} \rightarrow \mathrm{IU}$ & $4.390^{*}$ \\
$\mathrm{PEU} \rightarrow \mathrm{IU}$ & $4.935^{*}$ \\
$\mathrm{IU} \rightarrow \mathrm{SU}$ & $6.005^{*}$ \\
$\mathrm{FC} \rightarrow \mathrm{SU}$ & $2.546^{*}$ \\
\hline * t-table $>1.96$ &
\end{tabular}


Health Information System (HIS) is an essential part in health care service to collect reliable a data relates to decision making purpose on health. HIS performs several activities such as collecting, processing, storing and visualising to support decision maker in planning the health care services. In addition, HIS is integrated with health system improving the quality of health service [14]. In Indonesia, "Puskesmas" or Public Health Center or PHC roles as primer healthcare, they perform case finding and health service [15] directly to the community. Looking at the huge population in Indonesia, it would be related to the number of data that should be collected and managed. Accordingly, working with the effective and efficient system is the fundamental step to cut the time and money consuming. Also, in the health national insurance era in Indonesia, the role of PHC as first health care provider holds essential role to deliver a good data regarding the claims of the insurance. While, on the other hand, to run such technology, a human is a pivotal person to succeed because human initiates to conceptualising and implementing those technology [16]. Accordingly, assessment of HISforPHC acceptance among the user will bring an understanding of the factor associated with the HIS acceptance and may improve the HIS quality in the future.

In this study, we measured the factor associated with the human acceptance of HIS implementation. Through Technology Acceptance Model (TAM) approach, we identified that system use or actual use of HISforPHC significantly related to the Intention Use (IU) and Facilitating Condition (FC). While Intention of Use predicted considerably by Perceived Ease of Use (PEU) and Perceived of Usefulness (PU).

Terminology is significantly influencing the PU and PEU the HIS in Sebengkok PHC. Terminology plays a vital role to carried out the user understanding when operating the HIS regarding the program interface. Terminology clarity assists the user to input a data to the HIS in proper technique and faster. As a result, the user keeps on their mind that HIS gives a benefit to them and helpful to do their jobs. The same finding had found from another different research in Somalia who said terminology was associated with PEU [17]. On another hand, looking at the education background of the participant (Table 2) which is most of them have a university degree, probably it is a reason that participant easy to understand the terminology which used in the HIS. Perceived of usefulness is a valuable insight that has to form on the health information system implementation. Thus, associated with the willingness to use to use daily work if they understand that HIS is helpful and solve their duty. As well as for the perceived of ease to use, terminology help to encourage the user that they do not require a hard effort on using the HIS program. In line with this, research in the digital library has found the similar finding that terminology influences the perceived ease of use [18].

In this research also discovered that screen design significantly correlated perceived Ease of Use (PEU) of HIS. In line with this finding, a study found the same that screen design has a positive association with the PEU [19]. Screen design is the primary interface in HIS; user will directly interact with the system through this menu. Designing an exciting screen interface could be help user easily to find the menu. A research said that excellent screen design would make the user comfortable with the screen environment and user easy to play around the program $[19,20]$. Another research revealed that there are five determinants of the individual perception of the computer technology, one of which is screen design [21].

This study also elaborated that PEU and PU have a positive association with the Intention of Use (IU). This finding is approved by another research which stated behavioural intention is an indirect function from two variables that are perceived ease of use and perceived of usefulness [22]. The intention is a willingness of an individual to follow or participate in the particular program. This intention is an investment for a specific program to be successful in the implementation. Thus, it is supported by the social cognitive theory that IU as one of constructing actual behaviour [23].

Correspond with social cognitive theory; in this study found that IU has a positive association to System Use (SU) together with Facilitating Condition (FC). IU is defined by the subjective individual, while FC is influenced by the external situation such as the support of related health agencies to fulfil the infrastructures [24] such as good internet connection, qualified computer, and stable electricity to perform the system. As the best PHC in North Borneo [25], Sebengkok PHC has proper facilities including to run Health Information System. Accordingly, the HIS runs efficiently and support the routine work in the PHC in a proper way.

According to original TAM theory, it explains that technology usage determined by user behaviour which is an indirect function of Perceived Ease of Use (PEOU) and Perceived Usefulness (PU) [26]. Reflected that theory and considering this research result, terminology and screen design are the two crucial part of HIS implementation. This study may have a limitation on the sample size, which was conducted in one PHC in Indonesia. Result interpretation may perform carefully by considering the type of the PHC. 


\section{CONCLUSION}

Health information system management is an essential part of providing accurate and validates data to support the policy maker. Owing to the urgency of the data needs, health authority rolling out the PHC Health Information System as the first entry of the data from the community. In developing countries, such as in Indonesia, acceptance of HIS often becomes a problem due to the human resources and low awareness of the HIS importance. Accordingly, understanding user acceptance is essential to bring HIS closer to them. Even though a lot of effort improving user participation on HIS implementation likewise the identification factor associated with the acceptance has been done, more research is needed to know the acceptance among healthcare staff such midwife, nurse, general practitioner, pharmacist, etc. In addition, reviewing the acceptance through other parameters might enrich the insight for the policymaker.

\section{ACKNOWLEDGEMENTS}

We would like to thank the Tarakan District Health Office and Sebengkok Public Health Centre for helping us during the research. We also wish to thank all the participants who contributed to this study.

\section{REFERENCES}

[1] WHO/USAID/University of Oslo. Health Facility and Community Data [Internet]. WHO/USAID. Oslo: WHO Available from: http://www.who.int/healthinfo/facility_information_systems/governance_policies/en/, 2014.

[2] Grandia L. Healthcare Information Systems: A Look at the Past, Present, and Future [Internet]. Health Catalist.[cited 2018 Apr 23]. p. Analyst \& IT Roles, Business Intelligence and Tech. Available from: http://www.healthcatalyst.com/wp-content/uploads/2014/05/A-Look-at-the-Past-Present-and-Future-HealthcareInformation-Systems.pdf, 2018.

[3] Vital Wave Consulting. Health Information Systems in Developing Countries [Internet]. Vital wave consulting. Available from: http://www.minsa.gob.pe/ogei/conferenciaops/recursos/43.pdf, 2009.

[4] Wilson K, Lubinski D. Building Stronger Health Information Systems in the Developing World: Recommendations for Donors, Governments, and Nongovernmental Organizations Research Paper and Strategic Briefing " The obscure we see eventually . The completely obvious, it seems , [Internet]. Seattle; 2010. Available from: https://www.path.org/publications/files/TS_dhs_building_his_rpt.pdf

[5] WHO. Indonesia [Internet]. Web.[cited 2018 Jun 18]. Available from: http://www.who.int/country/idn/en, 2018.

[6] Indonesia Ministry of Health. SIKDA GENERIK Puskesmas: User Guideline [Internet]. Jakarta: Indonesia Ministry of Health. Available from: https://bidankomunitas.files.wordpress.com/2012/01/sikda-generik-panduanpengguna2.pdf, 2011.

[7] Farlinda S., "Assessment of Implementation Health Center Management Information System with Technology Acceptance Model ( TAM ) Method and Spearman Rank Test in Jember Regional Health Center," In: The 1st International Conference on Information Technology and Security, p. 263-7, 2014.

[8] Indonesia Ministry of Health. Data Base of Public Health Centre by December 2013 [Internet]. Vol. 53, Publikasi Data dan Informasi. Jakarta: Indonesia Ministry of Health. 1689-1699 p. Available from: http://www.depkes.go.id/folder/view/01/structure-publikasi-pusdatin-data-dasar-puskesmas.html, 2014.

[9] Aulia NR. Human, Organization and Technology Factors in the Using of SIMPUS Application for Patient Registration at Mulyorejo Public Health Centre, Surabaya. Indones J Public Heal, 12(August):237-48, 2017.

[10] Davis FD. Perceived Usefulness , Perceived Ease of Use , and User Acceptance of Information Technology. MIS Q [Internet]. 1989;13(3):319-40. Available from: http://links.jstor.org/sici?sici=0276-7783(198909)13:3\%3C319:PUPEOU\%3E2.0.CO;2-E

[11] Pramono AE. Public Helath Centre Management Information System Acceptance by Health Officer in Yogyakarta City. Universitas Gadjah Mada; 2016.

[12] Araimi FAF Al., "A Hypothetical Model to Predict the Potential Impact of Government and Management Support in Implementing Integrated Management of Childhood Illness Practices," Oman Med J, 32(3):221-6, 2017.

[13] Anderson JC, Gerbing DW. Structural equation modeling in practice: A review and recommended two-step approach. Psychol Bull [Internet]. 1988;103(3):411-23. Availablefrom: http://doi.apa.org/getdoi.cfm?doi=10.1037/0033-2909.103.3.411

[14] Yazdi-Feyzabadi V, Emami M, Mehrolhassani MH., "Health Information System in Primary Health Care: The Challenges and Barriers from Local Providers' Perspective of an Area in Iran," Int J Prev Med, 6(57), 2015.

[15] Soemitro D., "The challenge of e-Health in Indonesia," Bul Jendela Data dan Inf Kesehat, 1:1-14, 2016.

[16] Asan O, Carayon P., "Human Factors of Health Information Technology—Challenges and Opportunities," Int J Hum Comput Interact [Internet]. 33(4):255-7. Available from: http://dx.doi.org/10.1080/10447318.2017.1282755, 2017.

[17] Goon Tuck lee,. Factors Influence Perceived Usefulness \& Ease of Use of Digital Library Technology by PostGraduate Students in Malaysia. 2004.

[18] Muse M, Lecturer H, Sheik AY, Assistant A-P., "Impact of Interface Characteristics on the Perceived Ease of Use and Perceived Usefulness of Digital Library Adoption among Post - Graduate Students in Somalia," Eur J Bus Manag, 6(35):2222-839, 2014. 
[19] Darsono LI., "Examining Information Technology Acceptance by Individual Professionals," Gadjah Mada Int J Bus, 7(2):155-178, 2005.

[20] Oakleaf M., "Writing Information Literacy Assessment Plans: A guide to best practice," Commun Inf Lit, 3(2):8090, 2009

[21] Hong W, Thong JYL, Wong WM, Tam KY., "Determinants of User Acceptance of Digital Libraries: An empirical examination of individual differences and system characteristics," J Manag Inf Syst, 18(3):97-124, 2001.

[22] Tao D. Understanding Intention to Use Electronic Information Resources: A Theoretical Extension of the Technology Acceptance Model (TAM). In: AMIA Annual Symposium Proceedings [Internet]. 2008. p. 717-21. Availablefromhttp://www.ncbi.nlm.nih.gov/pmc/articles/PMC2656102/\%5Cnhttp://www.ncbi.nlm.nih.gov/pmc/art icles/PMC2656102/pdf/amia-0717-s2008.pdf

[23] Sheeran P., "Intention - Behavior Relations: A Conceptual and Empirical Review," Eur Rev Soc Psychol, 12(1):1-36, 2002.

[24] Phichitchaisopa N, Naenna T., "Factors Affecting the Adoption of Healthcare Information Technology," Excli J, 12:413-36, 2013

[25] Merdeka.com. Sebengkok Tarakan Health Center is the Best Urban PHC in North Kalimantan [Internet]. Merdeka.com. 2016 [cited 2018 Jun 12]. p. Berita. Available from: https://tarakan.merdeka.com/berita/puskesmassebengkok-tarakan-terbaik-tingkat-perkotaan-se-kaltara-1607178.html

[26] Casas CA., "Factors That Determine Attitudes Toward the Use Technology to Plan for Retirement: An Empirical Analysis," In: Proceedings of the 2010 Meeting of Academy for Financial Services [Internet]. 2010. p. 1-13. Available from: http://www.academyfinancial.org/wp-content/uploads/2013/10/6B-Casas.pdf 